\title{
Dietary glycemic load and gastric cancer risk in Italy
}

\author{
P Bertuccio*,', D Praud',2, L Chatenoud', E Lucenteforte', C Bosetti', C Pelucchi', M Rossi', E Negri' \\ and C La Vecchia ${ }^{1,3}$
}

'Istituto di Ricerche Farmacologiche 'Mario Negri', Via Giuseppe La Masa, 19, 20156 Milan, Italy; ${ }^{2}$ Institut d'Informatique et de Mathématiques Appliquées, Université Joseph Fourier, BP 53, 3804 I Grenoble Cedex 9, France; ${ }^{3}$ Istituto di Statistica Medica e Biometria 'Giulio A. Maccacaro', Università degli Studi di Milano, 20133 Milan, Italy

\begin{abstract}
We investigated gastric cancer risk in relation to dietary glycemic index (Gl) and glycemic load (GL), which represent indirect measures of carbohydrate absorption and consequently of dietary insulin demand, in a case-control study conducted in northern Italy between 1997 and 2007, including 230 patients with the incident, histologically confirmed gastric cancer and 547 frequency matched controls, admitted to the same hospitals as cases with acute non-neoplastic conditions. We used conditional logistic regression models, including terms for major recognised gastric cancer risk factors and non-carbohydrate energy intake. The odds ratios (ORs) in the highest vs lowest quintile were 1.9 (95\% Cl: 1.0-3.3) for Gl and 2.5 (95\% Cl: 1.3-4.9) for GL. Compared with participants reporting low GL and high fruits/vegetables intake, the OR rose across strata of high GL and low fruits/vegetables, to reach 5.0 ( $95 \%$ Cl: 2.2- I I.5) for those reporting low fruits/vegetables intake and high GL. Our study may help to explain the direct relation observed in several studies between starchy foods and gastric cancer risk. British Journal of Cancer (2009) 1 00,558-56I. doi:I0.1038/sj.bjc.6604894 www.bjcancer.com
\end{abstract} (C) 2009 Cancer Research UK

Keywords: case-control studies; dietary glycemic load; glycemic index; gastric cancer

A direct relation between starchy foods - particularly refined cereals - and gastric cancer has long been observed in studies conducted in Greece (Trichopoulos et al, 1985), Italy (La Vecchia et al, 1987) and Belgium (Tuyns et al, 1992), and has been confirmed in most subsequent studies (World Cancer Research Fund/American Institute for Cancer Research, 2007; Lucenteforte et al, 2008; Navarro Silvera et al, 2008). Refined cereals and starchy foods, particularly in southern Europe, considered indicators of a poorer diet, have been associated with increased gastric cancer risk (La Vecchia and Franceschi, 2000); they may be associated with a diet high in glycemic index (GI) and glycemic load (GL).

The GI is an indicator of the absorption rate of carbohydrates and ranks their effect on blood glucose concentrations. It compares available carbohydrates gram-for-gram in individual foods, providing a numerical, evidence-based index of postprandial glycemia (Jenkins et al, 1981, 1984; Gnagnarella et al, 2004). As the GL combines measures of carbohydrate (both qualitative and quantitative) and of dietary insulin demand, the overall GI reflects the average quality of carbohydrates consumed, whereas the total dietary GL reflects both their average quantity and quality (FosterPowell et al, 2002).

GI and, particularly, GL have been related to excess risk of colorectal (Augustin et al, 2002), breast (Augustin et al, 2001), oral and oesophageal (Augustin et al, 2003) cancers. Gastric cancer has also been associated with GI and GL in a case-control study in Italy (Augustin et al, 2004), though not in a Swedish cohort study

*Correspondence: Dr P Bertuccio; E-mail: bertuccio@marionegri.it Received II November 2008; revised 19 December 2008; accepted 19 December 2008
(Larsson et al, 2006). We have further considered the relation between GL, GI and gastric cancer risk using data from another Italian case-control study, based on a more detailed, reproducible and validated food frequency questionnaire (FFQ) (Lucenteforte et al, 2008).

\section{MATERIALS AND METHODS}

We derived data from a case-control study of gastric cancer conducted in 1997-2007 in the greater Milan area, Italy, the design of which has been described earlier (Lucenteforte et al, 2008). Briefly, cases were 230 patients ( 143 men, 87 women; median age 63 years, range $22-80$ years) admitted to major teaching and general hospitals in the study area with the incident, histologically confirmed stomach cancer (ICD IX 151.0-151.9), diagnosed no longer than 1 year before the interview, and with no earlier diagnosis of cancer. The control group included 547 patients (286 men, 261 women; median age 63 years, range 22-80 years) frequency matched to cases by age and sex (ratio of $2: 1$ for men and 3:1 for women), admitted to the same hospitals as cases for a wide spectrum of acute, non-neoplastic conditions, unrelated to risk factors for stomach cancer and long-term diet modification. Of these $20 \%$ were admitted for traumas, $23 \%$ for other orthopaedic conditions, $22 \%$ for acute surgical and $35 \%$ for other miscellaneous disorders. Less than $5 \%$ of cases and controls who were approached refused to be interviewed.

For both cases and controls, data were collected during their hospital stay by trained interviewers using a structured questionnaire covering socio-demographic characteristics, 
anthropometric measures, selected lifestyle habits, including tobacco and alcohol consumption, personal medical and family history of cancer. The patients' usual diet during the two years before diagnosis or hospital admission (for controls) was assessed through a reproducible (Franceschi et al, 1995) and valid (Decarli et al, 1996) FFQ covering 78 foods and beverages, including a range of the most common recipes in Italian diet. Participants indicated the average weekly frequency of consumption for each dietary item; intakes lower than once a week but at least once a month were coded as 0.5 per week. Energy and carbohydrate intake were computed from the FFQ using an Italian food composition database, integrated with other sources when needed (Salvini et al, 1998; Gnagnarella et al, 2004).

GI values were assigned to each food item using international tables (Foster-Powell et al, 2002). Daily average GI was calculated by summing the products of the carbohydrate content per serving for each food or food group, times the average number of servings of that food per week, times its GI (Wolever et al, 1994), all divided by the total amount of available carbohydrates. The daily average GL was computed as the GI, but without dividing by the total amount of carbohydrates.

Odds ratios (ORs) and their corresponding 95\% confidence intervals (CIs) for subsequent quintiles of GI and GL were estimated using conditional multiple logistic regression models, conditioned on age and sex (Breslow and Day, 1980). We considered two models: the first included terms for period of interview, education, body mass index, tobacco smoking, intake of fruits and vegetables, and family history of stomach cancer; the second also included non-carbohydrate energy intake, to allow for bias due to systematic over- or under-reporting (Willett and Stampfer, 1986).

\section{RESULTS}

Table 1 gives the distribution of gastric cancer cases and controls according to quintiles of GI and GL, and the corresponding multivariate ORs. The OR for the highest $v s$ the lowest quintile of GI was 2.1 (95\% CI: $1.2-3.6)$, with a significant trend in risk $(P=0.034)$. For GL, ORs were significantly above unity in the third $(\mathrm{OR}=2.5,95 \% \mathrm{CI}: 1.4-4.5)$, fourth $(\mathrm{OR}=2.7,95 \% \mathrm{CI}: 1.5-4.9)$ and highest quintile ( $\mathrm{OR}=2.7 ; 95 \% \mathrm{CI}$ : $1.5-4.8)$, with a significant trend in risk $(P<0.001)$. Continuous ORs for the difference between the 80th and 20th percentile (based on the control distribution) were 1.4 (95\% CI: $1.1-1.9)$ for GI and 1.5 (95\% CI: 1.2-2.0) for GL. After further adjustment for non-carbohydrate energy intake, the OR estimates were similar for both GI and GL.

Table 2 gives the continuous ORs of gastric cancer for GI and GL in strata of sex, age and major established risk factors for gastric cancer. No significant differences emerged in any strata of the covariates considered.

We further considered the combined effect of fruits/ vegetables intake and GL on gastric cancer risk. Compared with participants reporting low GL and high fruits and vegetables intake, the OR rose for increasing levels of GL, particularly in participants with low fruits/vegetables intake, to reach 5.0 (95\% CI: $2.2-11.5)$ for those reporting high GL and low fruits/vegetables intake.

\section{DISCUSSION}

This study, based on a valid and detailed FFQ, confirms and further quantifies the existence of a direct relation between GI, and mostly GL, and gastric cancer risk. We were able to allow in the analysis not only for major risk factors for gastric cancer, such as education, tobacco smoking and vegetables and fruits intake, but also for non-carbohydrate energy intake. Out results indicate that some characteristics of carbohydrates, in particular of such refined carbohydrates as white bread, pasta and rice, have an appreciable influence on gastric cancer risk in this population.

The findings are consistent with those of an earlier Italian casecontrol study, based on a shorter questionnaire, which found an approximately two-fold risk of gastric cancer for the highest quartile of GL, and only a modest association with GI (Augustin et al, 2004). They also agree with several earlier studies, indicating that a diet rich in cereals or starches is associated with an increased gastric cancer risk (Trichopoulos et al, 1985; La Vecchia et al, 1987; Tuyns et al, 1992; World Cancer Research Fund/ American Institute for Cancer Research, 2007; Lucenteforte et al, 2008; Navarro Silvera et al, 2008). They are, however, at variance with the findings of the Swedish Mammography Cohort (Larsson et al, 2006), which found no relation between GI and GL and gastric cancer risk.

Table I Odds ratios (ORs) and 95\% confidence interval (Cl) of gastric cancer among 230 cases and 547 controls, according to glycemic index and glycemic load. Italy, 1997-2007

\begin{tabular}{|c|c|c|c|c|c|}
\hline & Upper limit & Cases $n(\%)$ & Controls $n(\%)$ & $O^{a}(95 \% \mathrm{Cl})$ & $\mathrm{OR}^{\mathrm{b}}(95 \% \mathrm{Cl})$ \\
\hline I (low) & 73 & $28(12.2)$ & $110(20.1)$ & $1.0^{c}$ & $1.0^{c}$ \\
\hline III & 80 & $44(19.1)$ & $110(20.1)$ & $1.5(0.8-2.6)$ & $1.4(0.8-2.4)$ \\
\hline IV & 83 & $47(20.4)$ & $108(19.7)$ & $1.5(0.8-2.6)$ & $1.4(0.8-2.5)$ \\
\hline$\vee$ (high) & - & $67(29.1)$ & $110(20.1)$ & $2.1(1.2-3.6)$ & $1.9(1.0-3.3)$ \\
\hline$\gamma_{1}^{2}$ trend ( $P$-value) & & & & $4.5(P$-value $=0.034)$ & $3.0(P$-value $=0.083)$ \\
\hline \multicolumn{6}{|l|}{ Glycemic load } \\
\hline I (low) & 147 & $24(10.4)$ & $109(19.9)$ & $1.0^{c}$ & $1.0^{c}$ \\
\hline$\|$ & 183 & $30(13.0)$ & $110(20.1)$ & $1.4(0.7-2.5)$ & $1.3(0.7-2.5)$ \\
\hline III & 217 & $57(24.8)$ & $110(20.1)$ & $2.5(1.4-4.5)$ & $2.4(1.3-4.5)$ \\
\hline IV & 263 & $58(25.2)$ & $108(19.7)$ & $2.7(1.5-4.9)$ & $2.6(1.4-5.1)$ \\
\hline$\vee$ (high) & - & $61(26.5)$ & $110(20.1)$ & $2.7(1.5-4.8)$ & $2.5(1.3-4.9)$ \\
\hline$\chi_{1}^{2}$ trend $(P$-value $)$ & & & & I3.4 $(P$-value $<0.00 \mathrm{I})$ & $8.9(P$-value $=0.003)$ \\
\hline
\end{tabular}

${ }^{a}$ Estimates from conditional logistic regression models, conditioned on age and sex and adjusted for period of interview, only when indicated, education, body mass index, tobacco smoking, intake of fruits and vegetables, and family history of stomach cancer. ${ }^{b}$ Further adjusted for non-carbohydrate energy intake. ${ }^{c}$ Reference category. ${ }^{\mathrm{d}}$ The unit is the difference between the 80th and the 20th percentile. 
Table 2 Odds ratios (ORs) and 95\% confidence intervals (Cl) of gastric cancer among 230 cases and 547 controls, according to glycemic index and glycemic load in strata of selected covariates. Italy, 1997-2007

\begin{tabular}{|c|c|c|}
\hline \multirow{2}{*}{$\begin{array}{l}\text { Covariates } \\
\text { (no. of cases/no. of controls) }\end{array}$} & \multicolumn{2}{|c|}{ OR $(95 \% \mathrm{Cl})^{a, b}$} \\
\hline & Glycemic index & Glycemic load \\
\hline \multicolumn{3}{|l|}{ Sex } \\
\hline Men $(143 / 286)$ & I.I $(0.7-1.6)$ & $1.5(1.0-2.1)$ \\
\hline Women $(87 / 261)$ & $1.8(1.1-2.9)$ & $1.3(0.8-2.3)$ \\
\hline \multicolumn{3}{|l|}{ Age (years) } \\
\hline$<65(125 / 297)$ & $1.5(1.0-2.3)$ & $1.3(0.9-2.0)$ \\
\hline$\geqslant 65(105 / 250)$ & $1.3(0.8-2.1)$ & $1.7(1.1-2.7)$ \\
\hline \multicolumn{3}{|l|}{ Education $^{c}$ (years) } \\
\hline$<7(95 / 236)$ & $1.7(1.0-3.0)$ & $1.4(0.9-2.4)$ \\
\hline$\geqslant 7(132 / 307)$ & I.I $(0.8-1.6)$ & $1.4(0.9-2.0)$ \\
\hline \multicolumn{3}{|l|}{ Body mass index $\left(\mathrm{kg} \mathrm{m}^{-2}\right)$} \\
\hline$<25(118 / 248)$ & $1.2(0.8-1.8)$ & $1.3(0.8-2.0)$ \\
\hline$\geqslant 25(108 / 297)$ & $1.6(1.0-2.6)$ & $1.6(1.0-2.4)$ \\
\hline \multicolumn{3}{|l|}{ Smoking status ${ }^{c}$} \\
\hline Non-smoker (171/428) & $1.5(1.0-2.2)$ & $1.3(0.9-1.8)$ \\
\hline Smoker (58/। | 8) & $1.2(0.6-2.3)$ & $2.1(1.1-3.9)$ \\
\hline \multicolumn{3}{|l|}{ Intake of fruits (portions/week) } \\
\hline$\leqslant 15(117 / 273)$ & $1.5(1.0-2.3)$ & $1.5(1.0-2.2)$ \\
\hline$>15(113 / 274)$ & $1.6(1.0-2.5)$ & $1.4(0.9-2.2)$ \\
\hline \multicolumn{3}{|l|}{ Intake of vegetables (portions/week) } \\
\hline$\leqslant 9(|4| / 274)$ & $1.4(0.9-2.1)$ & $1.3(0.9-2.0)$ \\
\hline$>9(89 / 273)$ & $1.2(0.8-1.9)$ & $1.4(0.9-2.2)$ \\
\hline
\end{tabular}

${ }^{a}$ The unit is the difference between the 80 th and the 20 th percentile. ${ }^{b}$ Estimates from conditional logistic regression models, conditioned on age and sex and adjusted for period of interview, only when indicated, education, body mass index, tobacco smoking, intake of fruits and vegetables, family history of stomach cancer and noncarbohydrate energy intake. 'The sum does not add up to the total because of some missing values.

We also found that the role of GL is independent of other major dietary correlates for gastric cancer, including vegetables and fruits consumption, and that there was a five-fold difference in gastric cancer risk between participants reporting low GL and high fruits and vegetables intake and those reporting high GL and low fruits and vegetables consumption. Thus, two simple diet indicators determine substantial variation in gastric cancer risk.

A high GL diet may increase gastric cancer risk through the modulation of the insulin-like growth factors (IGFs). Insulin increases the activity of IGFs, such as IGF-1 (Gnagnarella et al, 2008), and suppresses hepatic secretion of IGF-binding protein-1. IGF-1 stimulates cell proliferation and differentiation, inhibits apoptosis (Kaaks and Lukanova, 2001; Gnagnarella et al, 2008) and increases production of vascular endothelial growth factors, important in tumour angiogenesis, and the expression of glucose transporters, glycolytic enzymes, and growth factors, which may promote tumor cell survival under hypoxic conditions (Akakura et al, 2001; Oh et al, 2008). Higher IGF-1 concentrations have been observed in patients with gastric cancer than in healthy controls (Franciosi et al, 2003). Insulin can also influence sex hormone concentrations and reduce the levels of their binding protein (Garzo and Dorrington, 1984; Poretsky and Kalin, 1987; Gnagnarella et al, 2008). Sex hormones have been linked to gastric cancer risk (La Vecchia et al, 1994), though this has been disputed (Bahmanyar et al, 2008; Persson et al, 2008).

A limitation of our study is the lack of information on Helicobacter pylori (H. pylori) infection. A recent study observed a positive association between plasma glucose concentration and risk of stomach cancer only among $H$. pylori-positive participants (Yamagata et al, 2005; Larsson et al, 2006). Though the prevalence of $H$. pylori infection is declining (Malaty, 2007), it was relatively high (about 45\%) in Italy in the mid 1990's. It increased with age and was more frequent in men than in women (Russo et al, 1999). Thus, a large proportion of the population studied is likely to be H. Pylori-positive.

Participation among eligible patients was almost complete, and the catchment areas for cases and controls were comparable. Hospital controls may differ in their dietary habits from the general population. However, we excluded control participants admitted for conditions associated with dietary modifications (diabetes mellitus, cardiovascular diseases, etc.). Recall bias is also unlikely, given that the association between various types of starches and gastric cancer was not evident at the time of interviews. Moreover, the similar hospital setting for cases and controls likely increased the comparability of dietary histories, and the questionnaire was reproducible and valid (Franceschi et al, 1995; Decarli et al, 1996; D’Avanzo et al, 1997).

With respect to confounding results, we adjusted for noncarbohydrate energy intake to control for potential systematic over- or under-reporting between cases and controls (Willett and Stampfer, 1986); further adjustment for several covariates failed to explain the association between GI and GL and gastric cancer.

Our study suggests that a diet high in GL and GI is directly related to gastric cancer risk, and may therefore help to explain the relation observed in several studies with starchy foods (Trichopoulos et al, 1985; La Vecchia et al, 1987; Buiatti et al, 1990; Tuyns et al, 1992).

\section{ACKNOWLEDGEMENTS}

This work was conducted with contribution from the Italian Association for Cancer Research (AIRC) and the Italian League Against Cancer. PB was supported by a fellowship from the Italian Foundation for Cancer Research (FIRC). The work of this paper was undertaken while CLV was a senior fellow at the International Agency for Research on Cancer, Lyon, France. The authors thank Ms I Garimoldi for editorial assistance.

\section{REFERENCES}

Akakura N, Kobayashi M, Horiuchi I, Suzuki A, Wang J, Chen J, Niizeki H, Kawamura K, Hosokawa M, Asaka M (2001) Constitutive expression of hypoxia-inducible factor-1alpha renders pancreatic cancer cells resistant to apoptosis induced by hypoxia and nutrient deprivation. Cancer Res 61: $6548-6554$

Augustin LS, Dal Maso L, La Vecchia C, Parpinel M, Negri E, Vaccarella S, Kendall CW, Jenkins DJ, Francesch S (2001) Dietary glycemic index and glycemic load, and breast cancer risk: a case-control study. Ann Oncol 12: $1533-1538$

Augustin LS, Franceschi S, Jenkins DJ, Kendall CW, La Vecchia C (2002) Glycemic index in chronic disease: a review. Eur J Clin Nutr 56: $1049-1071$

Augustin LS, Gallus S, Franceschi S, Negri E, Jenkins DJ, Kendall CW, Dal Maso L, Talamini R, La Vecchia C (2003) Glycemic index and load and risk of upper aero-digestive tract neoplasms (Italy). Cancer Causes Control 14: 657-662

Augustin LS, Gallus S, Negri E, La Vecchia C (2004) Glycemic index, glycemic load and risk of gastric cancer. Ann Oncol 15: 581-584 
Bahmanyar S, Lambe M, Zendehdel K, Nyren O, Boffetta P, Ye W (2008) Parity and risk of stomach cancer by sub-site: a national Swedish study. Br J Cancer 98: $1295-1300$

Breslow NE, Day NE (1980) Statistical Methods in Cancer Research. Vol. I. The Analysis of Case-Control Studies. IARC Sci Publ No. 32. IARC: Lyon, France Buiatti E, Palli D, Decarli A, Amadori D, Avellini C, Bianchi S, Bonaguri C, Cipriani F, Cocco P, Giacosa A, Marubini E, Minacci C, Puntoni R, Russo A, Vindigni G, Fraumeni Jr JF, Blot WJ (1990) A case-control study of gastric cancer and diet in Italy: II. Association with nutrients. Int $J$ Cancer 45: 896 - 901

D’Avanzo B, La Vecchia C, Katsouyanni K, Negri E, Trichopoulos D (1997) An assessment, and reproducibility of food frequency data provided by hospital controls. Eur J Cancer Prev 6: 288-293

Decarli A, Franceschi S, Ferraroni M, Gnagnarella P, Parpinel MT, La Vecchia C, Negri E, Salvini S, Falcini F, Giacosa A (1996) Validation of a food-frequency questionnaire to assess dietary intakes in cancer studies in Italy. Results for specific nutrients. Ann Epidemiol 6: 110-118

Foster-Powell K, Holt SH, Brand-Miller JC (2002) International table of glycemic index and glycemic load values: 2002. Am J Clin Nutr 76: 5-56

Franceschi S, Barbone F, Negri E, Decarli A, Ferraroni M, Filiberti R, Giacosa A, Gnagnarella P, Nanni O, Salvini S, La Vecchia C (1995) Reproducibility of an Italian food frequency questionnaire for cancer studies. Results for specific nutrients. Ann Epidemiol 5: 69-75

Franciosi CM, Piacentini MG, Conti M, Romano F, Musco F, Caprotti R, Rovelli F, Uggeri F (2003) IGF-1 and IGF-1BP3 in gastric adenocarcinoma. Preliminary study. Hepatogastroenterology 50: 297-300

Garzo VG, Dorrington JH (1984) Aromatase activity in human granulosa cells during follicular development and the modulation by folliclestimulating hormone and insulin. Am J Obstet Gynecol 148: 657-662

Gnagnarella P, Gandini S, La Vecchia C, Maisonneuve P (2008) Glycemic index, glycemic load, and cancer risk: a meta-analysis. Am J Clin Nutr 87: $1793-1801$

Gnagnarella P, Parpinel M, Salvini S, Franceschi S, Palli D, Boyle P (2004) The update of the Italian food composition database. J Food Comp Analysis 17: 509-522

Jenkins DJ, Wolever TM, Jenkins AL, Josse RG, Wong GS (1984) The glycaemic response to carbohydrate foods. Lancet 2: 388-391

Jenkins DJ, Wolever TM, Taylor RH, Barker H, Fielden H, Baldwin JM, Bowling AC, Newman HC, Jenkins AL, Goff DV (1981) Glycemic index of foods: a physiological basis for carbohydrate exchange. Am J Clin Nutr 34: $362-366$

Kaaks R, Lukanova A (2001) Energy balance and cancer: the role of insulin and insulin-like growth factor-I. Proc Nutr Soc 60: $91-106$

La Vecchia C, D’Avanzo B, Franceschi S, Negri E, Parazzini F, Decarli A (1994) Menstrual and reproductive factors and gastric-cancer risk in women. Int J Cancer 59: $761-764$

La Vecchia C, Franceschi S (2000) Nutrition and gastric cancer with a focus on Europe. Eur J Cancer Prev 9: $291-295$

La Vecchia C, Negri E, Decarli A, D’Avanzo B, Franceschi S (1987) A casecontrol study of diet and gastric cancer in northern Italy. Int J Cancer 40: $484-489$
Larsson SC, Bergkvist L, Wolk A (2006) Glycemic load, glycemic index and carbohydrate intake in relation to risk of stomach cancer: a prospective study. Int J Cancer 118: 3167 - 3169

Lucenteforte E, Scita V, Bosetti C, Bertuccio P, Negri E, La Vecchia C (2008) Food groups and alcoholic beverages and the risk of stomach cancer: a case-control study in Italy. Nutr Cancer 60: 577 - 584

Malaty HM (2007) Epidemiology of Helicobacter pylori infection. Best Pract Res Clin Gastroenterol 21: $205-214$

Navarro Silvera SA, Mayne ST, Risch H, Gammon MD, Vaughan TL, Chow WH, Dubrow R, Schoenberg JB, Stanford JL, West $\mathrm{AB}$, Rotterdam H, Blot WJ, Fraumeni Jr JF (2008) Food group intake and risk of subtypes of esophageal and gastric cancer. Int J Cancer 123: $852-860$

Oh SY, Kwon HC, Kim SH, Jang JS, Kim MC, Kim KH, Han JY, Kim CO, Kim SJ, Jeong JS, Kim HJ (2008) Clinicopathologic significance of HIFlalpha, p53, and VEGF expression and preoperative serum VEGF level in gastric cancer. BMC Cancer 8: 123

Persson C, Inoue M, Sasazuki S, Kurahashi N, Iwasaki M, Ye W, Tsugane S (2008) Female reproductive factors and the risk of gastric cancer in a large-scale population-based cohort study in Japan (JPHC study). Eur J Cancer Prev 17: 345 - 353

Poretsky L, Kalin MF (1987) The gonadotropic function of insulin. Endocr Rev 8: $132-141$

Russo A, Eboli M, Pizzetti P, Di Felice G, Ravagnani F, Spinelli P, Hotz AM, Notti P, Maconi G, Franceschi S, Ferrari D, Bertario L (1999) Determinants of Helicobacter pylori seroprevalence among Italian blood donors. Eur J Gastroenterol Hepatol 11: 867-873

Salvini S, Parpinel MT, Gnagnarella P, Maisonneuve P, Turrini A (1998) Banca dati di composizione degli alimenti per studi epidemiologici in Italia. Istituto Europeo di Oncologia: Milano

Trichopoulos D, Ouranos G, Day NE, Tzonou A, Manousos O, Papadimitriou C, Trichopoulou A (1985) Diet and cancer of the stomach: a casecontrol study in Greece. Int J Cancer 36: 291 - 297

Tuyns AJ, Kaaks R, Haelterman M, Riboli E (1992) Diet and gastric cancer. A case-control study in Belgium. Int J Cancer 51: 1-6

Willett W, Stampfer MJ (1986) Total energy intake: implications for epidemiologic analyses. Am J Epidemiol 124: 17-27

Wolever TM, Nguyen PM, Chiasson JL, Hunt JA, Josse RG, Palmason C, Rodger NW, Ross SA, Ryan EA, Tan MH (1994) Determinants of diet glycemic index calculated retrospectively from diet records of 342 individuals with non-insulin-dependent diabetes mellitus. Am J Clin Nutr 59: $1265-1269$

World Cancer Research Fund/American Institute for Cancer Research (2007) Food, Nutrition, Physical Activity, and the Prevention of Cancer: a Global Prospective. American Institute for Cancer Research: Washington, DC

Yamagata H, Kiyohara Y, Nakamura S, Kubo M, Tanizaki Y, Matsumoto T, Tanaka K, Kato I, Shirota T, Iida M (2005) Impact of fasting plasma glucose levels on gastric cancer incidence in a general Japanese population: the Hisayama study. Diabetes Care 28: 789-794 